\title{
NÚCLEO DE RENASCIMENTO ELISABETH KÜBLER-ROSS - NUREKR: ASSISTÊNCIA DE SAÚDE NO MODELO "HOSPICE"
}

\author{
REVIVAL CENTER ELIZABETH KÜBLER-ROSS - NUREKR: HOSPICE \\ MODEL HEALTH ASSISTANCE \\ NÚCLEO DE RENACIMIENTO ELISABETH KÜBLER-ROSS - NUREKR: \\ ASISTENCIA DE SALUD EN EL MODELO "HOSPICE"
}

\author{
Maria Teresa Mariotti de Santana' \\ Maria Femanda Cardoso Nascimento ${ }^{2}$ \\ Celso Fortes de Almeida ${ }^{3}$
}

\begin{abstract}
RESUMO:O "hospice" é um movimento relacionado com o "cuidar" do paciente e da familia diante da morte e do processo de morrer. Tem como recursos básicos: dar conforto e cuidados de enfermagem, acalmar e assistir o paciente, com liberdade total de visitas de seus familiares, atribuindo ao paciente e familia maior poder decisório do que teria em hospitais. O 'Hospice" não é um espaço geográfico, territorial, demarcado pelo que se denomina "instituiçăo". Mais do que isso, é um comportamento, uma postura diante do processo de morrer e da morte em si. O trabalho relata a experiência da atuação da equipe multiprofissional no modelo "hospice" implantado na Escola de Enfermagem da Universidade Federal da Bahia, onde ficou demonstrada a necessidade de conhecer e estudar tanatologia, ter uma mudança de atitude frente à morte e ao processo de morrer, e ter habilidade em lidar com a própria terminalidade.
\end{abstract}

PALAVRAS-CHAVE: enfermagem, tanatologia, paciente terminal

\section{INTRODUÇÃO}

O Núcleo de Renascimento Elisabeth Kúbler-Ross/NUREKR é um projeto destinado ao estudo da Enfermagem Intensivista e Tanatologia desenvolvido em conjunto com a disciplina Enfermagem Clínico-Cirúrgica II, no âmbito da graduação e pós-graduação, possuindo como parceiros, já com convênios de cooperação técnico-científica firmados: a Universidade Federal da Bahia através da Escola de Enfermagem/EEUFBa; a Instituição Tribo Arco-Íris/ITAI, instituição filantrópica, não-governamental que vem implantando na Bahia a assistência no modelo "HOSPICE".

O projeto a partir da sua implantação em 08 de maio de 1995, permitiu o contato com a morte e o processo de morrer dos clientes em seu contexto familiar e domiciliar, onde observouse a manifestação da consciência da terminalidade, surgida do confronto com uma doença incurável ou terminal, trazendo desestruturação, conflitos e mudanças.

O desgaste energético desta situação causa um "stress" de tal monta que quase sempre coloca estes clientes no abandono e no descaso, o que se reflete na atual situação do sistema de saúde: hospitais cada vez mais lotados devolvem o cliente para sua familia e esta, conflituada e inconformada com o resultado da assistência e sem saber o que fazer, retorna ao hospital de

'Enfermeira, Mestre, Professora da Escola de Enfermagem e Coordenadora do Núcleo de Renascimento Elisabeth Kübler-Ross INUREKR - da Universidade Federal da Bahia.

${ }^{2}$ Médica, Psicoterapeuta, Especializaçăo pela Pathwork Foundation, USA e formada pelo Instituto da Dinâmica Energética do Psiquismo, $B R$.

${ }^{3}$ Médico. Psicotereapeuta, formado pelo Instituto da Dinâmica Energética do Psiquismo, BR, Presidente da Instituiçäo Tribo Arco-Íris (ITAI), BR. 
origem ou outros, reiniciando-se, assim, o ciclo de desestruturação assistencial seja no âmbito domiciliar, ambulatorial ou hospitalar.

A assistência domiciliar prestada por esta equipe de saúde multidisciplinar, no programa, segue a concepção filosófica de "hospice", que é um movimento relacionado com o "cuidar" do cliente e de seus familiares diante da morte e do processo de morrer. "No 'hospice' não se prolonga inúltilmente nem se abrevia a vida. Simplesmente se vive, e, quando a morte chega, ela é recebida sem espanto, já que o morrer é encarado e trabalhado como sendo parte integrante da natureza humana. (Pessini,1995,p.67). Tem recursos básicos para dar conforto, cuidados de enfermagem e assistir o cliente com liberdade total de visitas de seus familiares, atribuindo ao cliente e familia maior poder decisório do que teria em hospitais.

O "hospice" não é um espaço geográfico, territorial, demarcado pelo que se denomina "instituição". Mais do que isso, é um comportamento, uma postura diante do processo de morrer e da morte em si que se caracteriza: pela necessidade de ouvir mais do que impor, de dar tempo, de compreender e tentar entender as mensagens e ensinamentos de cada ser; pela honestidade tanto em colocar para o cliente o seu real diagnóstico, em responder todas as suas perguntas, atendendo as necessidades especificas de cada caso; pela crença que é possivel morrer com dignidade, sem dor e com apoio, pois os clientes terminais identificam a consciência da aproximação da morte e freqüentemente controlam o tempo e as circunstâncias deste momento final, até que suas necessidades estejam satisfeitas.(Callanan e Kelley, 1994. p.18)

Compreender e admitir este comportamento, esta postura é o que permite aos profissionais de saúde oferecer condições especiais de assistência aos clientes e familias, ao tempo em que modificam sua postura pessoal diante da própria morte, pois as pessoas que estão morrendo têm muito a dizer, exigir, pedir e dar.

\section{O PROGRAMA ASSISTENCIAL DO NUREKR}

Na concepção filosófica do "hospice", o NUREKR tem como principal meta assegurar um atendimento humanizado, despertando uma mudança de atitude em relação à morte e ao processo de morrer, através de uma assistência multidisciplinar em âmbito predominantemente domiciliar.

Tem como objetivos: prestar serviço de assistência domiciliar ao cliente terminal e familia, através de práticas e processos de caráter assistencial e preventivo que gerem uma mudança de atitudes frente à morte e ao processo de morrer, realizada por uma equipe multidisciplinar, coordenada por um enfermeiro. A clientela deste programa compreende todas as pessoas que entrem em contato com as perdas em quaisquer niveis, sejam o físico, o emocional, o mental ou o espiritual, através de doenças, acidentes, mortes súbitas, envelhecimento e que tenham consciência desta terminalidade. Inclui, neste caso, os profissionais de saúde, pois no seu cotidiano se confrontam com o processo de morrer ou a morte em si das pessoas aos seus cuidados. Na equipe cada um atua conforme sua especialidade, antes, durante e depois da morte do paciente, junto aos familiares inclusive na elaboração do luto.Todos os profissionais só iniciam o atendimento domiciliar após terem cumprido o Programa de Treinamento do NUREKR, condição sem a qual o profissional não poderá compor a equipe multidisciplinar.

\section{A ATUAÇÃO DA EQUIPE MULTIPROFISSIONAL DE SAÚDE}

A coordenação executiva deste programa é da responsabilidade da Escola de Enfermagem, uma vez que a assistência domiciliar é coordenada por um enfermeiro. A coordenação médica é da responsabilidade da ITAI.

Foi constituida a Comissão Executiva, formada pelas entidades parceiras. Sua 
competência e finalidade consiste em: assegurar a politica geral do NUREKR em concordância com a Escola de Enfermagem e a ITAI; promover os meios necessários para assegurar ao NUREKR a realização de seus objetivos; promover a integração entre assistência, ensino, pesquisa e extensão; analisar e decidir sobre o convênio de cooperação técnico-cientifica celebrado entre a Escola de Enfermagem e a ITAI, para a execução do NUREKR; elaborar seu próprio regimento; exercer o poder disciplinar nos limites da sua competência e segundo o convênio estabelecido.

A inserção dos clientes no Programa de Assistência à Saúde no modelo - "HOSPICE" é feita pela demanda espontânea, divulgação nos meios de comunicação, convênios realizados com a rede básica de saúde e pela indicação dos profissionais. Os clientes, respeitados os critérios de admissão, são submetidos à avaliação da Comissão Executiva do NUREKR, que efetivará o cadastramento.

O cadastramento do cliente e familia no programa de Assistência "Hospice" segue os critérios: residir no Distrito Sanitário Barra/Rio-Vermelho; estar constatado pelo médico assistente que a expectativa de vida do cliente é limitada e apresentar um relatório sucinto do caso clínico; estarem extintos todos os procedimentos terapêuticos da medicina ortodoxa e o foco do tratamento tornar-se o conforto e o cuidado; ter familiares que se responsabilizem e aceitem os termos de assistência domiciliar oferecida pelo NUREKR; permitir a integração desta assistência ao ensino e pesquisa. Cadastrado o cliente, o Coordenador do NUREKR confeccionará a escala dos profissionais, cabendo a estes realizar a avaliação diagnóstica das necessidades do cliente e familia e a elaboração do Planejamento Assistencial, com um cronograma de visitas. Cada enfermeiro executa o Plano Assistencial que será integrado com os demais profissionais da equipe multidisciplinar.

A equipe multidisciplinar é formada por médicos, enfermeiros, fisioterapeutas, terapeutas ocupacionais, assistentes sociais, psicólogos, nutricionistas, grupo de voluntários e pastoral. Toda a equipe atuará antes, durante e após a morte do cliente, junto aos familiares no luto, cada um conforme sua especialidade.

OS ENFERMEIROS e os MÉDICOS farão uma visita domiciliar semanal, no mínimo, e solicitarão os profissionais necessários a cada caso, os quais farão seus programas de atendimento; oS PSICÓLOGOS, em sua primeira visita, definirão a participação do cliente e familia nos grupos de apoio, a depender de suas necessidades e conforme cada caso. Este se reunirá, em local previamente estabelecido, quinzenalmente; os ASSISTENTES SOCIAIS farão uma visita mensal, no minimo e indicarão os suportes de infra-estrutura necessários a cada caso; OS NUTRICIONISTAS, FISIOTERAPEUTASE TERAPEUTAS OCUPACIONAIS, chamados pelo enfermeiro responsável, definirão seus programas de atendimento a depender da necesssidade de cada caso; O GRUPO DE VOLUNTÁRIOS se dividirá em equipes de suporte, divulgação, jurídica, recursos, luto e administrativa; atuará junto ao cliente e família, integrada à equipe multidisciplinar; a PASTORAL que responderá pela assistência espiritual , atenderá mediante solicitação do próprio paciente e familia, respeitada sua crença religiosa.

A equipe multidisciplinar se reunirá uma vez a cada 15 (quinze) dias, convocada pelo Coordenador do NUREKR, para supervisão de apoio discussão de casos e levantamento de questões oriundas do atendimento domiciliar por parte dos profissionais.

Serão adotados os seguintes critérios para avaliação da assistência domiciliar do NUREKR: coeficiente de frequência da equipe multidisciplinar em suas diferentes atividades; número de pacientes e familia em processo de atendimento; coeficiente de produtividade baseado em número de atendimentos, convênios estabelecidos; quantidade de renda gerada e qualidade da mudança de atitudes frente à terminalidade; empenho dos profissionais e estudantes de saúde envolvidos no atendimento; atitudes de familiares e membros da comunidade que estejam envolvidos com a assistência. 


\section{CONSIDERAÇÖES FINAIS}

Esse cuidar envolveu a atuação do enfermeiro na área de ensino em virtude do treinamento em "hospice" necessário ao próprio profissional, aos auxiliares de enfermagem, voluntários, e todos os profissionais envolvidos na assistência. Na área da gerência o desempenho voltou-se para a previsão e provisão de materiais e equipamentos, seleção de pessoal, elaboração de escalas de serviço, reuniões administrativas, captação dos clientes. $\mathrm{Na}$ assistência, prestada em domicilio, foi avaliada a evolução clínica, integração da equipe multiprofissional com a familia, e o desenvolvimento de técnicas complementares junto aos clientes. O resultado alcançado foi a descoberta de uma outra forma de cuidar da pessoa que está morrendo, assegurando um atendimento em quaisquer níveis, sejam o físico, o emocional, o mental e/ou espiritual.

ABSTRACT: The hospice model is a movement concerned with the care of the dying patient and its family. It's main aim is to comfort and give nursing assistance to terminal patients, giving the patient and family more decision making power than it would have in regular hospitals. The Hospice is not a geographic, territorial space, defined as what we call an "institution". It is more than that, it is an attitude, a behavior towards death and dying. This paper reports on the experience of a multiprofessional team' which implemented hospice model care in the Nursing School of the Federal University of Bahia. The study showed that there is a need to understand and study tanathology, to change one's changing attitude towards death and dying, and to develop the ability to deal with one's own terminability

KEYWORDS: nursing, tanathology, terminat patient

RESUMEN: "Hospice" es un movimiento relacionado con el "cuidado"del paciente y de la familia ante la muerte y el proceso de morir. Tiene como recursos básicos: dar consuelo y asistencia de enfermeria, calmar y asistir al paciente, con total libertad para que los familiares lo visiten atribuyendo asi al enfermo y a la familia un poder de decisión mayor del que tendria en los hospitales. El "Hospice" no es un espacio geográfico, territorial que está demarcado por lo que se denomina "institución". Más que eso, se trata de un comportamiento, una actitud ante el proceso de morir y de la muerte en si. El trabajo relata la experiencia de la actuación del equipo multiprofesional en el modelo "hospice" que fue implantado en la Escuela de Enfermeria de la Universidad Federal de Bahia, en donde quedó demostrada la necesidad de conocer y estudiar tanatologia; la de que tiene que haber un cambio de actitud frente a la muerte $y$ al proceso de morir y la de tener una habilidad para tratar con la propia terminalidad

PALABRAS CLAVE: enfermería, tanatología, paciente terminal

\section{REFERÊNCIAS BIBLIOGÁFICAS}

CALLANAN, Maggie; KELLEY, Patricia. Gestos finais: compreendendo a consciência, necessidades e mensagens dos doentes terminais. São Paulo: Nobel, 1994. 176 p.

PRESSINI, Leocir. Eutanásia e América Latina: questões ético-teológica. São Paulo: Ed.Santuário, 1995. $251 \mathrm{p}$.

\section{Recebido em abril de 2000 \\ Aprovado em outubro de 2000}

